\title{
EVOLUTION OF THE MICROSTRUCTURE AND TEXTURE DURING ANNEALING OF A NIOBIUM STABILIZED FERRITIC STAINLESS STEEL
}

\author{
Rodrigues, D. G. ${ }^{1}$, ; Gonzalez, B. M. ${ }^{1}$; de Oliveira, T. R. ${ }^{2}$; de Alcantara, C.M. ${ }^{2}$ \\ ${ }^{1}$ Department of Metallurgical and Materials Engineering of Universidade Federal de Minas Gerais, Belo Horizonte, Minas Gerais, Brasil \\ ${ }^{2}$ Aperam South America, Timóteo, Minas Gerais, Brasil
}

*rodrigues_dg@yahoo.com.br

\begin{abstract}
The ferritic stainless steels are materials used in several segments due the excellent combination of mechanical properties and corrosion resistance. The properties of these alloys are strongly dependent on the microstructural characteristics and texture. Thus, knowledge of the microstructure and texture development is essential to optimize the mechanical properties. The aim of this study was to analyze the evolution of recrystallization and texture of a ferritic stainless steel stabilized with niobium, type AISI430. The samples cold rolled to a reduction in thickness of $85 \%$ were annealed by applying heating rate of $41.5^{\circ} \mathrm{C} / \mathrm{s}$. The annealing was interrupted at 780,830 and $880^{\circ} \mathrm{C}$ to verify the microstructure and texture changes. The nominal annealing temperature was $880^{\circ} \mathrm{C}$ and the soaking time was $25 \mathrm{~s}$. The technique used to characterize the changes in microstructure and texture was optic microscopy and high resolution Electron Backscatter Diffraction (EBSD). The samples removed at 780,830 and $880^{\circ} \mathrm{C}$ were partially recrystallized with the matrix composed of non-recrystallized and recrystallized regions. The recrystallized grains were observed mainly in prior high angle boundaries. The $\square$-fiber was more intense than $\square$-fiber at $780^{\circ} \mathrm{C}$ and $830^{\circ} \mathrm{C}$. On the other hand, at $880^{\circ} \mathrm{C}$ it was observed a decrease in intensity of $\square$-fiber and an increase $\square$-fiber intensity. These results indicate that the grains of the $\square$-fiber, with low stored energy, are consumed during the process of recrystallization.
\end{abstract}

